\title{
Chromatographic immunoassay based detection of human toxoplasmosis in District Mardan, Khyber Pakhtunkhawa, Pakistan
}

\author{
Mudassir Shah ${ }^{1,2}$, Muhammad Zahid ${ }^{1 *}$, Basmina Bibi ${ }^{1}$, Arab Hussain ${ }^{1,3}$, \\ Muhammad Haroon ${ }^{4}$ and Basit Ali ${ }^{1}$ \\ 1. Department of Zoology, Islamia College Peshawar, Khyber Pakhtunkhwa (KPK)-Pakistan \\ 2. Department of Zoology, Government Superior Science College Peshawar-Pakistan \\ 3. Department of Zoology, Government Post Graduate College Charsadda-Pkistan \\ 4. Khyber Teaching Hospital Khyber Pakhtunkhwa (KPK)-Pakistan \\ *Corresponding author's email: drmzahid@icp.edu.pk \\ Citation \\ Mudassir Shah, Muhammad Zahid, Basmina Bibi, Arab Hussain, Muhammad Haroon and Basit Ali. \\ Chromatographic immunoassay based detection of human toxoplasmosis in District Mardan, Khyber Pakhtunkhawa, \\ Pakistan. Pure and Applied Biology. Vol. 6, Issue 4, pp1297-1305. http://dx.doi.org/10.19045/bspab.2017.600138 \\ Received: 30/06/2017 Revised: 05/10/2017 \\ Accepted: 07/10/2017 \\ Online First: 16/10/2017
}

\section{Abstract}

This study was carried out to determine the sero-prevalence of human Toxoplasmosis in district Mardan, Pakistan. A total of 600 human blood samples were collected by random sampling method. Blood samples were analyzed for Toxoplasma gondii infection and anti-T. gondii IgM and IgG antibodies by using Latex agglutination test (LAT) and Chromatographic technique, respectively. Out of 600 individuals, 105 (17.5\%) were sero-positive for T. gondii. Males showed slightly higher $(18.4 \%)$ prevalence as compared to female $(16 \%)$, but statistically the difference was non-significant $\left(X^{2}=0.394, \mathrm{P}=0.5302\right)$. Sero-prevalence was high $(29.41 \%)$ in age group 31 - 45 years and lowest $(10 \%)$ in age group $\leq 1-15$ years. A non-significant difference $(\mathrm{P}>0.05)$ of sero-positivity was observed between rural (18.06\%) and urban (15.56\%) areas. Seropositivity for IgG was high (24\%) in age group 31-45. IgM anti-body showed highest seropositivity $(14 \%)$ in age group 61-75. Of various risk factors, a significant association $(\mathrm{P}=$ 0.0001) was found between sero-positivity and no hand washing after contact with animal, soil or other contaminated objects. However, there was no significant relation between sero-positivity of $T$. gondii and educational status of subjects ( $\mathrm{p}>0.05$ ).

Keywords: Chromatographic technique; Latex agglutination test; Human toxoplasmosis; Seroprevalence; Mardan

\section{Introduction}

Toxoplasmosis is a widely prevalent, zoonotic infection, caused by an obligate, intracellular protozoan parasite, commonly cosmopolitan in its distribution across the globe [1-3]. The disease condition is of considerable importance, particularly in hot and humid climates $[4,5]$ infecting about one third of the human population at global level [6, 7]. The sero-prevalence of toxoplasmosis in human populations is quite high in developing world, ranging up to $80 \%$ 
as compared to developed world [8]. Felines or cats are the definitive hosts as it has been shedding the oocysts of $T$. gondii in its feces in a routine excretion. Other domestic animals like cattle, goats, sheep, pigs, mice, rats and rodents are also known for transmitting toxoplasmosis to human $[3,9$, 10]. Placental transmission is also evident from mother to fetus whereas blood transfusion is the other possible cause $[3,11$, 12]. However, the major risk factor for human toxoplasmosis is the consumption of undercooked meat or food stuffs contacted by any intermediate host (sheep, rabbit, cat, mice and goat) containing tissue cysts [13, 14]. However, contact with animal, gardening and under cooked food and vegetables are the risk factors for human toxoplasmosis $[1,15,16]$. Above all, cats possess high risk of toxoplasmosis for human $[10,17,18]$. Toxoplasmosis is known for causing life threatening infections, including pneumonia, chorioretinitis, and encephalitis [19]. During pregnancy, mother infection leads to mental retardation, epilepsy, blindness and maternal death [13] or spontaneous abortion of the fetus [8, 20-22]. The present study aimed to record the sero-prevalence of toxoplasmosis in human population of District Mardan, Khyber Pakhtunkhwa, Pakistan. This investigation will further open new gates for the molecular level approaches to $T$. gondii infection in the region and will help in general awareness of the subjects about the detrimental health hazards of toxoplasmosis.

\section{Materials and methods}

The present study investigated the seroprevalence of $T$. gondii antibodies in human population of District Mardan, Khyber Pakhtunkhwa Pakistan. A total of 600 blood samples were collected by random sampling method. The study area was enough vast, that is why random sampling method was the best choice for conducting such a human oriented study. Blood samples were collected from male and female hosts by visiting different urban and rural areas of the district. Data was collected on properly designed questionnaire. For the study, ethical certificate was obtained from Islamia College University Peshawar. The data collection questionnaire included information like host name, sex, age, location, animal contact, educational level, use of washed or unwashed fruits and hand washing after animal sanitation or contact with soil. A total of $3 \mathrm{ml}$ blood was drawn from vein of each host's arm with disposable sterilized syringes. Blood samples were immediately transferred to laboratory for serum separation by centrifugation at $4000 \mathrm{rpm}$ (Revolution per minute) for 10 minutes. After processing, serum was transferred by micropipette into clear and labeled tubes.

\section{Serological tests}

All test samples were analyzed for $T$. gondii infection by using the Latex agglutination test (LAT). The kit was used according to the manufacturer protocol (Rosario, Argentina). Positive samples were preceded for detection of particular $\operatorname{IgM}$ and $\operatorname{IgG}$ antibodies by chromatographic immunoassay. For this purpose, OnSite Toxo IgG/IgM Rapid Test kits (CTK Biotech, Inc. USA) were used.

\section{Chromatographic immunoassay}

The OnSite Toxo IgG/IgM Rapid Test kit (CTK Biotech, Inc. USA) was used which is a lateral flow chromatographic immunoassay for the immediate detection and demarcation of $\operatorname{IgM}$ and IgG antiToxoplasma gondii in humans' serum. It is a simple, rapid, one step screening test and requires no special precautions.

\section{Assay procedure}

2-3 drops of serum were dispensed into the sample vail after removing air bubbles. Single drop sample diluent (PhosphateSaline buffer) was added. After timer setting, results were read after 15 minutes. 
Positive results were noticeable in one minute. The manifestation of any reddishpurple color in the $\mathrm{T}$ bands, apart from intensity, was considered as presence of the band.

\section{Statistical analysis}

To consolidate the results and check its statistical significance, chi square test was applied to calculate the P- value. The level of significance was selected $<0.05$. Data was analyzed through computer software SPSS (version 10.0-registered).

\section{Results}

\section{Sex-wise prevalence}

There were $69(18.40 \%)$ out of 375 infected in male and $36(16.00 \%)$ out of 225 were found toxoplasma positive in female. Over all sero-positivity for toxoplasmosis was high $(18.40 \%)$ in male sex as compared to females $(16.00 \%)$ (Table 1). Chi square $\left(\mathrm{X}^{2}\right)$ value was 0.394 against $\mathrm{P}=0.5302$. Although a difference was recorded in infection in both the sexes, but statistically the difference was non-significant. Male sex showed the highest sero-positivity for $\operatorname{IgG}$ $42(61 \%)$ than IgM $21(30 \%)$, and IgM than IgG+IgM 06 (09\%). Female sero-positivity for $\mathrm{IgG}, \operatorname{IgM}$ and $\mathrm{IgG}+\operatorname{IgM}$ was $42 \%, 25 \%$ and 33\%, respectively. Out of 600 tested samples for sero-prevalence of Toxoplasma gondii, 57 were IgG positive (10\%), 30 were IgM positive $(05 \%)$ and only $18(3 \%)$ were positive for both type of immunoglobulins.

Table 1. Gender wise T. gondii antibodies distribution in human population

\begin{tabular}{|c|c|c|c|c|c|c|}
\hline \multirow{2}{*}{ Gender } & \multirow{2}{*}{$\begin{array}{l}\text { Individual } \\
\text { Examined }\end{array}$} & \multicolumn{2}{|c|}{$\begin{array}{l}\text { Infected No; Percentage and Types } \\
\text { of Antibodies }\end{array}$} & \multirow{2}{*}{ Total } & \multirow{2}{*}{ Prevalence (\%) } \\
\cline { 3 - 5 } & & IgG & IgM & IgG +Ig & & \\
\hline Male & 375 & $42(61 \%)$ & $21(30 \%)$ & $06(09 \%)$ & 69 & $18.40 \%$ \\
\hline Female & 225 & $15(42 \%)$ & $09(25 \%)$ & $12(33 \%)$ & 36 & $16.00 \%$ \\
\hline Total\% & 600 & $57(9.5 \%)$ & $30(05 \%)$ & $18(03 \%)$ & 105 & $17.5 \%$ \\
\hline
\end{tabular}

$* \mathrm{P}=0.5302$

$* * X^{2}=0.394$

Level of significance $=0.05$

Age-wise prevalence

Sero-positivity of anti T. gondii IgG, IgM and $\mathrm{IgG}+\operatorname{IgM}$ was observed in relation to participant's age. Individuals in age group, 01 to 15 years showed highest seropositivity (05.00\%) for $\operatorname{IgM}, 03.00 \%$ for $\mathrm{IgG}$ and only $02.00 \%$ for $\operatorname{IgG}$ and $\operatorname{IgM}$ both. Highest IgG sero-prevalence $(24.00 \%)$ was observed in 31-45 years old group. Whereas the highest sero-positivity of $\operatorname{IgM}$ was $14.00 \%$ in the oldest group (61-75 years old) (Table 2). There was a difference in seropositivity for $\operatorname{IgG}+\operatorname{IgM}$ among different age groups. However both age groups (31- 45 and $61-75$ years) showed no $\operatorname{IgG}+\operatorname{IgM}$ positivity (Table 3 ).

Table 2. Age wise Sero-prevalence of human toxoplasmosis

\begin{tabular}{|c|c|c|c|}
\hline $\begin{array}{c}\text { Age group } \\
\text { (years) }\end{array}$ & No of hosts Examined & No of hosts infected & Prevalence (\%) \\
\hline$\leq 1-15$ & 174 & 18 & 10.34 \\
\hline $16-30$ & 240 & 39 & 16.25 \\
\hline $31-45$ & 102 & 30 & 29.41 \\
\hline $46-60$ & 63 & 12 & 19.04 \\
\hline $61-75$ & 21 & 06 & 28.57 \\
\hline Total & 600 & 105 & 17.5 \\
\hline
\end{tabular}


Table 3. Age wise Sero-prevalence of human toxoplasmosis by using IgG, IgM and IgG+Igm antibodies

\begin{tabular}{|c|c|c|c|c|c|c|c|}
\hline \multirow{2}{*}{$\begin{array}{c}\text { Age } \\
\text { groups }\end{array}$} & \multicolumn{2}{|c|}{ Anti body IgG } & \multicolumn{2}{c|}{ Anti body IgM } & \multicolumn{2}{c|}{ Anti body IgG+ IgM } & \multirow{2}{*}{ Positive } \\
\cline { 2 - 7 } & Negative & Positive & Negative & Positive & Negative & Positive & \\
\hline$\leq 1-15$ & $168(97 \%)$ & $6(3 \%)$ & $165(95 \%)$ & $9(5 \%)$ & $171(98 \%)$ & $3(2 \%)$ & 174 \\
\hline $16-30$ & $222(92 \%)$ & $18(8 \%)$ & $231(96 \%)$ & $9(4 \%)$ & $228(95 \%)$ & $12(5 \%)$ & 240 \\
\hline $31-45$ & $78(76 \%)$ & $24(24 \%)$ & $96(94 \%)$ & $6(6 \%)$ & $102(100 \%)$ & $*$ & 102 \\
\hline $46-60$ & $57(90 \%)$ & $06(10 \%)$ & $60(95 \%)$ & $3(5 \%)$ & $60(95 \%)$ & $3(5 \%)$ & 63 \\
\hline $61-75$ & $18(86 \%)$ & $03(14 \%)$ & $18(86 \%)$ & $3(14 \%)$ & $21(100 \%)$ & $*$ & 21 \\
\hline $\begin{array}{c}\text { Total } \\
(\%)\end{array}$ & $543(90 \%)$ & $57(10 \%)$ & $570(95 \%)$ & $30(05 \%)$ & $582(97 \%)$ & $18(03 \%)$ & 600 \\
\hline
\end{tabular}

\section{Area-wise prevalence}

To investigate toxoplasmosis in relation to area, 465 samples were collected from rural areas and 135 samples from the urban areas of the study population in Mardan district. The results were statistically tested to know any significant difference in sero-prevalence across the rural and urban areas. The difference was non-significant $(\mathrm{P}=0.5004$, significance level $=0.05)$. Toxoplasmosis was recoded $18.06 \%(\mathrm{n}=84 / 465)$ in rural and $15.56 \%(\mathrm{n}=21 / 135)$ in urban areas.
Chi square Value was 0.454 , as nonsignificant at 0.05 level of significance. 465 rural samples, $84(18.06 \%)$ were found positive for anti $\mathrm{T}$. gondii antibodies and 381 (81.94\%) were negative and among 135 urban samples, $21 \quad(15.56 \%)$ were seropositive for $\mathrm{T}$. gondii antibodies and 114 $(84.44 \%)$ were sero-negative. The prevalence was slightly higher in rural areas than urban areas (Table 4). However the difference was statistically non- significant $\left(X^{2}=0.454, P=0.5004\right)$.

Table 4. Area wise sero-prevalence of Toxoplasmosis

\begin{tabular}{|c|c|c|c|c|c|}
\hline Test Result & Rural & \% & Urban & \% & Total \\
\hline Negative & 381 & 81.94 & 114 & 84.44 & 495 \\
\hline Positive & 84 & 18.06 & 21 & 15.56 & 105 \\
\hline Total & 465 & 100 & 135 & 100 & 600 \\
\hline
\end{tabular}

$* X^{2}=0.454, \mathrm{P}=0.5004$

$* *$ Level of significance $=0.05$

\section{Risk factors for transmission}

In relation to mode of transmission, there were 411 individuals noted for contact with animals. Out of $41,19 \%$ were sero-positive for the parasite antibodies. Subjects having no association with the animals showed only $14 \%$ sero-positivity. It seems that animals' contact is positively associated factor with the infection. But difference observed in both groups was statistically non-significant $\left(\mathrm{X}^{2}=1.46, \mathrm{P}=0.2269\right)$. People used to wash their hands after animal and soils contact showed $10 \%$ sero-positivity and those not washing their hands were with $28 \%$ seropositive. An extremely significant difference $\left(X^{2}=22.36, \quad P=0.0001\right)$ was observed between the groups. Most of the infected individuals $(18 \%)$ were unaware about the infection and mode of toxoplasmosis transmission. While those having knowledge about the transmission mode were with 14\% sero-positivity. But the difference was again statistically non-significant $\left(X^{2}=0.491, P=\right.$ $0.4835)$. There was also a slight difference $\left(X^{2}=0.016, P=0.8993\right)$ in the sero-positivity of individuals using unwashed raw 
vegetables and fruits. And those using washed vegetables and fruits were having $18 \%$ and $17 \%$ ratios respectively for toxoplasmosis. People with soil contact were with higher $(08 \%)$ sero-positivity than those having no contact with $(4.75 \%)$ soil. However the difference is statistically insignificant (Table 5). The result shows, the prevalence of toxoplasmosis was higher
(20\%) in individuals, having secondary education than those having higher studies $(18 \%)$ and none or primary education (having 14\% infection). However, there was no statistically significant relation between sero-positivity to $\mathrm{T}$. gondii and educational standard of the study subjects $(\mathrm{P}>0.05 ; \mathrm{P}=$ 0.3848).

Table 5. Potential risk factors for $T$. gondii sero-positivity in human population

\begin{tabular}{|c|c|c|c|c|c|}
\hline Risk Factor & $\begin{array}{l}\text { No. } \\
\text { person's }\end{array}$ & No. positive (\%) & Chi-square & P-value & Significance \\
\hline \multicolumn{6}{|l|}{$\begin{array}{l}\text { Animal } \\
\text { contact }\end{array}$} \\
\hline Yes & 411 & $78(18.97)$ & 1.46 & 0.2269 & non-significant \\
\hline No & 189 & $27(14.28)$ & & & \\
\hline \multicolumn{6}{|l|}{$\begin{array}{l}\text { Hand } \\
\text { washing } \\
\text { after animal } \\
\text { contact }\end{array}$} \\
\hline Yes & 355 & $36(10.14)$ & 22.36 & 0.0001 & highly significant \\
\hline No & 245 & $69(28.16)$ & & & \\
\hline \multicolumn{6}{|l|}{$\begin{array}{l}\text { Knowledge } \\
\text { about } \\
\text { transmutation } \\
\text { mode }\end{array}$} \\
\hline Yes & 90 & $13(14.44)$ & 0.491 & 0.4835 & non-significant \\
\hline No & 510 & $92(18.03)$ & & & \\
\hline \multicolumn{6}{|l|}{$\begin{array}{l}\text { Unwashed } \\
\text { raw } \\
\text { Vegetables } \\
\text { Or fruits } \\
\text { consumption }\end{array}$} \\
\hline Yes & 75 & $14(18.66)$ & 0.016 & 0.8993 & non-significant \\
\hline $\mathrm{No}$ & 525 & $91(17.33)$ & & & \\
\hline \multicolumn{6}{|l|}{$\begin{array}{l}\text { Grading or } \\
\text { contact } \\
\text { with soil }\end{array}$} \\
\hline Yes & 200 & $16(8.00)$ & 2.25 & 0.1336 & non-significant \\
\hline No & 400 & $19(4.75)$ & & & \\
\hline
\end{tabular}

* Level of significance $=0.0$

\section{Discussion}

During the study, 600 samples having age range less than or equal to 01 to 75 years were studied for Toxoplasma gondii seropositivity. Out of total 600,105 subjects were found seropositive for anti-T. gondii 
immunoglobulin. Overall sero-prevalence of human toxoplasmosis was found to be 17.5 $\%$. The findings of Sadaruddin recorded $17.4 \%$ sero-prevalance of $T$. gondii in the capital territory of Pakistan in school going children [23]. A study from Tehran, Iran reported $17.7 \% \quad T$. gondii infection [24]. However, the findings of other authors have also reported a high sero-prevalence rate in China [25], Pakistan and Ethopia. Seroprevalence was recorded $37 \%$ in district Muzaffargarh, Punjab, Pakistan [16], 29.5\% in Dera Ghazi khan, Punjab [26] and 90\% in African population of Ethiopia [27]. The work done in Pakistan, Iran and china [2325] are in full agreement with our findings (Table 1). However, variations are evident in the prevalence rate of $T$. gondii infection across different regions, societies and countries. That might be due to different cultural activities, nutritional habits, socioeconomic condition, immunity, geographical region, animal contact, sample size, use of raw or not properly cooked meat, unfiltered water, contaminated soil, hygienic conditions and climatic change among regions [28-30].

Regarding sero-prevalence in different sexes, our data recoded a slightly higher prevalence in male sex as compared to female sex. However, the difference was statistically non-significant ( $p>0.05)$. The possible explanation for the slight change may be the difference in human activities and immune system [28], Klein had reported similar findings of higher occurrence of infections in males as compared to females due to immune system differences [31]. The intrinsic physiological changes between females and males might be another reason in difference of frequency in different sexes [32]. High rate of $T$. gondii infection in males was also reported from Punjab, Pakistan [16] which is in agreement with this findings. Our findings (Table 1) are further confirmed by the work of Moschen who also reported a slight dominance among males $(18.2 \%)$ than females $17.5 \%$ in Italy [33].

Prevalence of toxoplasmosis varies in different age groups. Lowest seroprevalence $(10 \%)$ was observed in the case of subjects with age 01 year or below to 15 years, while in age group 31-45 years, highest anti-T. gondii prevalence $(29.41 \%)$ was recorded. Age group 61-75 years also showed nearly same higher prevalence $(28.57 \%)$ of human toxoplasmosis (Table 2). Our data shows a higher infection in older age group as compared to younger age groups which is in accordance with the work of Tasawar who found $29.41 \%$ seroprevalence in age group 51-60 years [16]. Work of earlier authors also supports the present findings of high rate of $T$. gondii infection in old age groups. Likely, study conducted in the neighboring province Lahore, Pakistan showed a high rate of toxoplasmosis (28\%) in 51-60 years age group [9]. Reason for higher infection rate with the increasing age may increase the exposure time and the weakness of the immune system in old age people. Table 3 shows that, highest IgG positivity (24\%) in age group 31-45. While IgM higest seropositivity (14\%) is recorded in old age groups (61-75). On the other hand the highest $(05 \%)$ sero-positivity for $\mathrm{IgG}+\operatorname{IgM}$ is seen in age group16-30 and 46-60. The work of Ngui is in agreement with the present results (Table 3), who also recorded highest IgG sero-positivity than IgM and IgG+IgM [34]. While Mohan reported highest (10\%) IgM positivity in 6-12 years age group in urban area and $17.7 \%$ highest IgM positivity in age less than or equal to 05 years in the rural area [35]. Statistically a non-significant $(\mathrm{p}>0.05)$ difference was noted in toxoplasmosis infection recorded in rural and urban areas in our findings (Table 4), which correlates with the earlier work 
[36]. While some studies evaluated higher sero-prevalence in rural areas [37].

The effects of various factors such as the animal contact, hand washing after contact, knowledge about transmission modes, unwashed raw vegetables or fruits consumption, gardening or contact with soil were studied (Table 5). A significant association $(\mathrm{P}=0.0001)$ was found between hand washing after contact with soil, animal or infection. Previous studies support the association between these factors and toxoplasmosis infection [36]. In the current study, no significant connection $(\mathrm{P}>0.05)$ was observed between the $T$. gondii seropositivity and such factors due to small sample size.

\section{Conclusions}

It is concluded that the risk of infection increases with the increase in age, nonwashing of hands after animal and soil contact. Men remain slightly at higher risk as compared to females. Infection occurs in urban areas as well as in rural. IgG seropositivity is high in 31-45 age group, while IgM sero-positivity recorded high in old age group (61-75). Public awareness is sought through health programmes, as the infection is prevalent equally in both educated and non-educated subjects. Preventive measures should be taken to ensure public health and avoid its detrimental health effects. Hands should properly be washed, undercooked meal should be avoided, proper hand washing is required and animals contact should be avoided.

\section{Authors' contributions}

Conceived and designed the experiments: $\mathrm{M}$ Zahid, Performed the experiments: M Shah \& S Attaullah, Analyzed the data: M Haroon \& B Ali, Contributed reagents/ materials/ analysis tools: B Bibi \& A Hussain, Wrote the paper: M Zahid, \& M Shah.

\section{References}

1. Dubey JP \& Jones JL (2008). Toxoplasma gondii infection in humans and animals in the United States. International Journal Parasitology 38: 1257-1278.

2. Aldebret D, Hypolite M, Cavaillaes P, Touque B, Flori P, Loeuillet C \& Cesbron-Delauw MF (2011). Development of High-Throughput methods to quantify cysts of Toxoplasma gondii. Cytometry Part A 79: 952-958.

3. Shah M, Zahid M., Sthanadar AA \& Asmat P (2014). Seroprevalence of Toxoplasma gondii infection in human population of Mohmand Agency, Pakistan. Pakistan Journal of Zoology 46(4): 1169-1172.

4. Al-Qureshi AR, Ghandour AM, Obeid OE, Al-Mulhim A \& Makki SM (2001). Seroepidemiological study of Toxoplasma gondii infection in the human population in the Eastern region. Saudi Medical Journal 22(1): 13-8.

5. Shah M, Zahid M, Asmat P \& Sthanadar AA (2013b). Seroprevalence of Toxoplasma gondii in goats and sheep of district Mardan, Pakistan. International Journal of Biosciences 3: 90-97.

6. Jones JL, Kruszon-Moran D, SandersLewis K \& Wilson M (2007). Toxoplasma gondii infection in the United States, 1999 2004, decline from the prior decade. The American Journal Tropical Medicine and Hygiene 77: 405-410.

7. Kijlstra A \& Jongert E (2008). Control of the risk of human toxoplasmosis transmitted by meat. International Journal of Parasitology 38: 1359-1370.

8. Arevalo JF, Belfort RJR, Muccioli C \& Espinoza JV (2010). Ocular Toxoplasmosis in the developing world. International Ophthalmology Clinical 50: 57-69.

9. Ahmad MS, Maqbool A, Mahmood-UlHassan M, Mushtaq-Ul Hassan M \& ANJUM AA (2012). Prevalence of 
Toxoplasma gondii antibodies in human beings and commensal rodents trapped from Lahore. Pakistan Journal Animal Plant Sciiences 22(1): 51-53.

10. Robert-Gangneuxa \& Darde ML (2012). Epidemiology of and Diagnostic Strategies for Toxoplasmosis. Clini. Microbio. Rev 25(2): 264-296.

11. Hajsoleimani F, Ataeian A, Nourian AA \& Mazloomzadeh S (2012). Seroprevalence of Toxoplasma gondii in pregnant women and bioassay of $\operatorname{IgM}$ positive cases in Zanjan, Northwest of Iran. Iranian Journal of Parasitology 7(2): 82-86.

12. Bodaghi B, Touitou V, Paris CFL \& Lehoang P (2012). Toxoplasmosis: new challenges for an old disease. Eye 26: 241-244.

13. Montoya JG \& Liesenfeld O (2004). Toxoplasmosis. Lancet 363(9425): 1965 1976.

14. Shah M, Zahid M, Sthanadar AA, Pir A, Kausar A \& Jan AH (2013a). Seroprevalence of Toxoplasma gondii infection in domestic animals of Mohmand agency, Pakistan Journal of Coastal Life Medicence 1(1): 70-73.

15. Dubey JP \& Beattie CP (1988). Toxoplasmosis of Animals and Man. CRC Press, Boca. Raton, Florida 1-220.

16. Tasawar Z, Raza AA, Aziz F \& Lashari MH (2012). Prevalence of Human Toxoplasmosis in District Muzaffargarh, Punjab. Gomal Journal of Medical Sciences 10(1): 37-41.

17. Mcallister MM (2005). A decade of discoveries in veterinary protozoology changes our concept of "subclinical" toxoplasmosis. Veterinary parasitology 132: 241-247.

18. Kolbekova P, Kourbatova E, Novotnal M, Kodym P \& Flegr J (2007). New and old risk-factors for Toxoplasma gondii infection: prospective cross sectional study among military personnel in the
Czech Republic. Clinical Microbiology and Infection 13: 1012-1017.

19. Cantos GA, Prando MD, Siqueira MV \& Teixeira RM (2000). Toxoplasmosis: occurrence of antibodies antiToxoplasma gondii and diagnosis. Revista Da Associação Médica Brasileira 46(4): 335-41.

20. Martin S (2001). Congenital Toxoplasmosis. Neonatal Netw 20(4): 23-30.

21. Lopes-Mori RMF, Breganó RM, Capobiango JD, Inoue IT, Reiche EMV, Morimoto HK, Casella AMB, Bittencourt LHF, Freire RL \& Navarro IT (2011). Programs for control of congenital toxoplasmosis. Associação Médica Brasileira 57(5): 581-586.

22. Cabanas RMP, Araujo EJA, Da-Silva AV \& Santana DMG (2012). Myenteric neuronal plasticity induced by Toxoplasma gondii (genotype III) on the duodenum of rats. Anais da Academia Brasileira de Ciencias 84(3): 737-745.

23. Sadaruddin A, Agha F, Anwar F \& Ghafoor A (1991). Seroepidemiology of Toxoplasma gondii infection in young school children in Islamabad. Journal of Pakistan Medical Association 41: 131134.

24. Soleimani Z, Salekmoghadam A, Shirzadi M \& Pedram N (2003). Seroepidemiological study of Toxoplasma gondii in high school girls in Robatkarim, district by IFA and ELISA. Proceeding of 4th national congress of parasitology and parasitic diseases, Mashhad. Iran 388.

25. Sun X, Lu H, Jia B, Chang Z, Peng S, Yin J, Chen Q \& Jiang N (2013). A comparative study of Toxoplasma gondii seroprevalence in three healthy Chinese populations detected using native and recombinant antigens. Parasite Vectors 6: 1-241. 
26. Tasawar Z, Nawaz S, Lashari MH, Aziz F \& Hayat CS (2011). Seroprevalence of human Toxoplasmosis in Dera Ghazi Khan, Punjab. Gomal Journal of Medical Sciences 9(1): 82-85.

27. Shimelis T, Tebeje M, Tadesse E, Tegbaru B \& Terefe A (2009). Seroprevalence of latent T. gondii infection among HIV-infected and HIVuninfected people in Addis Ababa, Ethiopia: A comparative cross-sectional study. BMC Research Notes 2: 213.

28. Ortiz-Alegria LB, Caballero-Ortega $\mathrm{H}$, Canedo- Solares I, Rico-Torres CP, Sahagun-Ruiz A \& Medina-Escutia ME (2010). Congenital toxoplasmosis: candidate host immune genes relevant for vertical transmission and pathogenesis. Genes and Immununity 11: 363-73.

29. Sroka S, Bartelheimer N, Winter A, Heukelbach J, Ariza L, Ribeiro H, Oliveira FA, Queiroz AJN, Alencar C \& Liesenfeld O (2010). Prevalence and risk factors of toxoplasmosis among pregnant women in Fortaleza, Northeastern Brazil. The American journal of tropical medicine and hygiene 83: 528-33.

30. Dhumne M, Sengupta C, Kadival G, Rathinaswamy A \& Velumani A (2007). National Seroprevalence of $T$. gondii in India. Journal of Parasitolology 93: 1520-1.

31. Klein SL (2004). Hormonal and immunological mechanisms mediating sex differences in parasite infection. Parasite Immunology 26: 247-64.

32. Mcclelland EE \& Smith JM (2011). Gender specific differences in the immune response to infection. Archivum immunologiae et therapiae experimentalis 59: 203-13.

33. Moschen ME, Stroffolini T, Arista S, Pistoia D, Giammanco A, Azara A, Mattia DE, Chiaramonte, M, Rigo G \& Scarpa B (1991). Prevalence of Toxoplasma gondii antibodies among children and teenagers in Italy. Microbiology 14: 229-34.

34. Ngui R, Yvonne AL, Lim Amir NF, Nissapatorn V \& Mahmud R (2011). Seroprevalence and Sources of Toxoplasmosis among Orang Asli (Indigenous) Communities in Peninsular Malaysia. The American journal of tropical medicine and hygiene 85(4): 660-666.

35. Mohan B, Dubey ML, Malla N \& Kumar R (2002). Seroepidemiological study of toxoplasmosis in different sections of population of Union Territory of Chandigarh. The Journal of communicable diseases 34(1): 15-22.

36. Studenicova $\mathrm{C}$, Bencaiova $\mathrm{G} \&$ Holkova R (2006). Seroprevalence of Toxoplasma gondii antibodies in a healthy population from Slovakia. European journal of internal medicine 17: 470-473.

37. Kawashima T, Win KS, Kawabata M, Barzaga N, Matsuda H \& Konishi E (2000). Prevalence of antibodies to Toxoplasma gondii among urban and rural residents in the Philippines. The Southeast Asian journal of tropical medicine and public health 31(4): 742746. 